\title{
AVALIAÇÃO DOS EFEITOS TÓXICOS DO AGROQUÍMICO TORDON® SOBRE OS ORGANISMOS TESTE Lactuca sativa E Allium cepa.
}

\section{EVALUATION OF THE TOXIC EFFECTS OF TORDON® AGROCHEMICAL ON TEST}

\author{
ORGANISMS Lactuca sativa AND Allium cepa.
}

\author{
Hugo MARTINS', Franco Dani CAMPOS-PEREIRA²
}

1 - Especialização em Biotecnologia, Centro Universitário Hermínio Ometto - UNIARARAS, Araras, SP. - ORIENTANDO

2 - Instituto de Ciências da Saúde, Universidade Paulista - UNIP, Limeira, SP. - ORIENTADOR Autor para correspondência: hugomartins151@hotmail.com

\section{RESUMO:}

O uso de agroquímicos na agricultura gera diversos danos ao meio ambiente, e a contaminação por essas substâncias podem representar sérios riscos à saúde humana e a de outros organismos não alvo. Diante disso, o objetivo deste trabalho foi analisar os efeitos do herbicida Tordon ${ }^{\circledR}$ sobre os parâmetros de fitotoxicidade em alface (Lactuca Sativa) e sobre os parâmetros de genotóxicidade e mutagênicidade em células meristemáticas de Allium cepa expostas a diferentes concentrações da substância obtidas por diluições seriadas. Foram analisadas concentrações (Controle Negativo, Controle Positivo, 100\% (substância pura), 10\%, 1\%, 0,1\%, 0,01\%, 0,001\%, 0,0001\%, 0,00001\% e 0,000001\%). Nos resultados foram observados efeitos genotóxicos e mutagênicos para as maiores concentrações revelando uma curva dose resposta, onde as menores concentrações avaliadas apresentaram os menores índices de toxicidade. Mais estudos devem ser realizados uma vez que este ainda é um estudo preliminar.

Palavras-chave: Herbicida, fitotoxicidade, genotoxicidade,

\section{ABSTRACT:}

The use of agrochemicals in agriculture generates several damages to the environment, and a contamination by these substances can pose serious risks to human health and other non-target organisms. The objective of this study was to analyze the effects of the herbicide Tordon $^{\circledR}$ on the parameters of phytotoxicity in lettuce (Lactuca Sativa) and on the parameters of genotoxicity and mutagenicity in meristematic cells of Allium cepa exposed to different concentrations of the substance obtained by serial dilutions. Concentrations were analyzed (Negative Control, Positive Control, 100\% (pure substance), 10\%, 1\%, 0.1\%, $0.01 \%, 0.001 \%, 0.0001 \%, 0.00001 \%$ and $0.000001 \%)$. The results demonstrated genotoxic and mutagenic effects for the highest concentrations, revealing a dose response curve, where the lowest concentrations evaluated had the lowest toxicity indices. Further studies should be conducted as this is still a preliminary study.

Key-words: Herbicide, phytotoxicity, genotoxicity,

\section{INTRODUÇÃO}

O uso de agroquímicos é muito comum na agricultura Brasileira e mundial, visando 
um aumento de nutrientes no solo, correção do pH e eliminação de pragas. Entretanto, muitos destes produtos podem trazer danos à saúde humana, e causar uma série de problemas e contaminações ambientais (RAMALHO, 2000). Entre os danos causados a organismos expostos por agentes químicos, os efeitos genotóxicos e mutagênicos têm se mostrado preocupantes, devido à sua capacidade de induzir danos genéticos, que podem levar a vários problemas de saúde e também afetar as gerações futuras, uma vez que essas alterações podem ser herdadas (LEME, MARIN-MORALES, 2009).

De acordo com Mansano et al. (2013), grande parte deste material não chega a atingir o organismo-alvo. Desta forma, ao atingir os cursos e reservatórios de água, dependendo das características físicas e químicas do produto, os resíduos podem contaminá-lo, serem absorvidos e acumulados em organismos não alvo e podendo então ser acumulados ao longo do tempo (RAMALHO, 2000; COPATTI et al., 2009).

O Tordon ${ }^{\circledR}$ é um herbicida recomendado para o controle de dicotiledôneas de porte arbustivo em áreas de pastagens e plantações. Possui em sua formulação o composto 4amino-3,5,6-tricloro ácido picolínico (Picloram) e o ácido 2,4-Diclorofenoxiacético (2,4-D) (ADAPAR, 2018).

O Picloram se caracteriza por ser um produto extremamente ativo em dicotiledôneas, sendo comum seu uso em misturas com outros herbicidas, como 2,4-D. Ele é um herbicida com alto potencial de contaminação de águas subterrâneas, pois apresenta longa persistência no solo (meia-vida de 90 dias), podendo ser encontrado na área de aplicação até dois ou três anos após a aplicação (SANTOS et al., 2006).

De acordo com Van Epps (1974) e Isensee (1971), o picloram e as misturas que contêm picloram, apresentam uma melhor ação sobre caules maduros, e também inibem a germinação da raiz de forma mais eficiente que os herbicidas habituais do tipo fenoxi.

O 2,4-Diclorofenoxiacético (2,4-D) tem sido amplamente utilizado desde a década de 40 , e possui em sua formulação, subprodutos como dioxinas, que são altamente tóxicas (GRISOLIA, 2005).

O uso de pulverizações de 2,4-D em pastagens tem sido utilizada por quase 20 anos, mas ainda não foram relatados dados sobre a presença de resíduos de 2,4-D no leite de vacas. Os dados publicados sobre os resíduos no leite quando o ácido 2,4-D foi ingerido diretamente por vacas ou pulverizado na forragem foram negativos com os métodos disponíveis para análise (KLINGMAN, 1966).

Os fenóis e as anilinas cloradas, presentes na formulação do $\operatorname{Tordon}^{\circledR}$, são introduzidos diretamente no ambiente por meio do uso abusivo e excessivo de 
agroquimicos que contenham esses compostos. Segundo Park (1999), estes compostos são bastante tóxicos, e a sua toxicidade tende a aumentar com o seu grau de cloração. Além de produtos químicos como os herbicidas, pesticidas, inseticidas e fungicidas, esses fenois tambem podem ser introduzidos no ambiente por meio de derramamentos acidentais e por meio da liberação ilegal de águas residuais industriais e municipais (STEIERT, 1987).

Bioensaios com plantas apresentam vantagens para serem realizados em avaliações ambientais, pois são considerados sensíveis e de fácil realização, quando comparados aos bioensaios que utilizam animais (FERNANDES et al., 2007). O sistemateste $A$. cepa é amplamente utilizado em monitoramento de contaminações ambientais, por ser um teste de resposta rápida, de baixo custo e favorável na avaliação de danos cromossômicos e alterações no ciclo mitótico, devido à presença de boas condições cromossômicas, como cromossomos grandes e em número reduzido (2n=16) (LEME, MARIN-MORALES, 2009). Grant (1982) e Caritá, Marin-Morales (2008) descrevem A. cepa como um eficiente sistema teste de rotina, para avaliar o potencial genotóxico de substâncias químicas, devido à sua sensibilidade e boa correlação com sistemas teste de mamíferos.

O bioensaio de germinação e crescimento radicular de alface (Lactuca sativa) está entre os testes biológicos disponíveis para avaliar os efeitos de contaminantes ambientais O teste consiste em expor as sementes desta planta a um agente potencialmente tóxico, que estabelece subsequentemente o número de sementes germinadas, bem como o grau de alongamento da raiz (PALMIERI et al., 2014). Tais ensaios com plantas vasculares são particularmente interessantes, porque permitem a avaliação dos efeitos adversos de um composto tóxico na germinação e crescimento das raízes, mesmo nos estágios iniciais do desenvolvimento da semente, tornando o processo consideravelmente mais simples e mais rápido (CARVALHO et al., 2013). O ensaio de germinação e crescimento de raiz são técnicas simples, rápidas, confiáveis e econômicas (CUNHA, 2005). Além disso, uma vez que a raiz é o primeiro órgão a entrar em contato com o substrato ou solução que contém a substância a ser analisada, alguns autores recomendam a realização dos ensaios de avaliação da germinação e crescimento da raiz para verificar a fitotoxicidade potencial de substâncias (VALERIO et al., 2007). Diante disso, o objetivo deste trabalho foi analisar os efeitos sobre os parâmetros de fitotoxicidade em Lactuca Sativa e sobre os parâmetros de genotóxicidade e mutagênicidade em células meristemáticas de $A$. cepa expostas a diferentes concentrações do herbicida Tordon ${ }^{\circledR}$ obtidas por meio de diluições seriadas. 


\section{MATERIAL E MÉTODOS}

\subsection{Substância e concentrações utilizadas}

O herbicida $\operatorname{Tordon}^{\circledR}$ é registrado no Ministério da Agricultura, Pecuária e Abastecimento (MAPA) sob no 0358709. Possui em sua composição 402 g/L de 2,4-D e 103,6 g/L de Picloram. O produto foi obtido comercialmente através da COOPERATIVA AGROPEC JACUTINGA LTDA, na cidade de Ouro Fino - MG. Os experimentos foram desenvolvidos utilizando concentrações de exposição obtidas a partir de uma diluição seriada do produto comercial em água destilada (Tabela 1).

\begin{tabular}{cc}
\hline \multicolumn{2}{c}{ Concentrações Utilizadas } \\
\hline $\mathbf{1 0 0} \%$ & Produto puro \\
$\mathbf{1 0} \%$ & $10^{1} \%$ \\
$\mathbf{1} \%$ & \\
$\mathbf{0 , 1} \%$ & $10^{-1} \%$ \\
$\mathbf{0 , 0 1 \%}$ & $10^{-2} \%$ \\
$\mathbf{0 , 0 0 1} \%$ & $10^{-3} \%$ \\
$\mathbf{0 , 0 0 0 1 \%}$ & $10^{-4} \%$ \\
$\mathbf{0 , 0 0 0 0 1} \%$ & $10^{-5} \%$ \\
$\mathbf{0 , 0 0 0 0 0 1 \%}$ & $10^{-6} \%$ \\
\hline
\end{tabular}

\subsection{Ensaio de germinação e de crescimento de raízes}

O ensaio foi realizado em triplicata de acordo com Sobrero e Ronco (2004). As placas foram forradas com papel filtro e em cada uma foram dispostas 30 sementes de $L$. sativa (Alface crespa Grand rapids, lote: 7896026037211) que germinaram em $5 \mathrm{~mL}$ de cada concentração de Tordon ${ }^{\circledR}$ demonstradas na tabela 1. As placas foram cobertas com folha de alumínio para evitar a influência da luz e mantidas durante 96 h em incubadora B.O.D à $24^{\circ} \mathrm{C}$. Após esse período foram calculados a porcentagem de sementes germinadas (total de sementes germinadas/total de sementes dispostas por placa x100) (PALMIERI et al., 2014) e os comprimentos de raízes foram medidos com um paquímetro digital. De acordo com Lutterbeck (2015), foram calculados a porcentagem relativa de 
sementes germinadas (SG) (1), a porcentagem de crescimento de raiz (CR) (2) e o índice de germinação (IG) (3).

$$
\begin{gathered}
\text { (1) } S G=\frac{\text { Sementes germinadas }}{\text { Sementes germinadas em controle }} \times 100 \\
\text { (2) } C R=\frac{\text { Comprimento médio da raiz }}{\text { Comprimento médio da raiz controle }} \times 100 \\
\text { (3) } I G=\frac{(S G) \times(C R)}{100}
\end{gathered}
$$

\subsection{Bioensaios com sementes de Allium cepa}

Sementes de A. cepa, foram dispostas em placas de Petri forradas com papel de filtro para germinação nas diferentes concentrações do Herbicida Tordon ${ }^{\circledR}$, como demonstrado na tabela 1.

Como controle negativo foi utilizado água ultra-pura, e o controle positivo com solução aquosa de metano sulfonato de metila (MMS) na concentração de $4 \times 10^{-4} \mathrm{M}$ (SigmaAldrich, CAS 66-27-3). Todos os testes com germinação de sementes foram realizados em triplicata. As radículas, com aproximadamente $2,0 \mathrm{~cm}$ de comprimento, foram coletadas e em seguida, fixadas em solução de Carnoy (Álcool - Ácido Acético 3:1 - $v / v$ ) por 6 a $18 \mathrm{~h}$ em temperatura ambiente. Após este tempo, o fixador foi trocado por um novo, recémpreparado. Posteriormente, as raízes ficaram armazenadas em geladeira, a $4^{\circ} \mathrm{C}$, até a sua utilização na confecção das lâminas para os ensaios de aberrações cromossômicas (AC) e de micronúcleo (MN).

\subsection{Ensaios de AC e Teste do MN em células meristemáticas e F1}

O teste de $A C$ e $M N$ em células meristemáticas de radículas de $A$. cepa foram realizados de acordo com o protocolo de Grant (1982), com algumas modificações. As radículas fixadas foram submetidas à coloração em reativo de Schiff. Para preparar as lâminas, os meristemas foram colocados em lâminas contendo uma gota de carmim acético $2 \%$ e recobertos com lamínulas, com um suave esmagamento. As lamínulas foram retiradas em nitrogênio líquido e as lâminas permanentes foram montadas com resina sintética, para 
posterior análise. Para a análise de AC, foram considerados diversos tipos de aberrações (fragmentos, perdas, pontes, aderências cromossômicas, entre outros) nas diferentes fases da divisão celular (prófase, metáfase, anáfase e telófase). Foi considerado como endpoint de genotoxicidade, todas as aberrações cromossômicas observadas, exceto as quebras cromossômicas. Já como indicativo de mutagenicidade, foram consideradas as quebras cromossômicas e a presença de $\mathrm{MN}$. A análise dos parâmetros acima citados foi realizada pela contagem de cerca de 5000 células para cada tratamento, sendo 500 células por lâmina, em um total de 10 lâminas avaliadas (MAZZEO et al., 2015).

Para a obtenção dos índices mitóticos (IM) foram consideradas as porcentagens das células em divisão, seguindo a aplicação da fórmula a seguir (4).

$$
\text { (4) } I M=\frac{\text { NÚMERO DE CÉLULAS EM DIVISÃo }}{\text { TOTAL DE CÉLULAS OBSERVADAS }} \text { X100 }
$$

A genotoxicidade foi avaliada pela obtenção do índice de células portadoras de aberrações cromossômicas (IAC) e anormalidades nucleares (AN), segundo a fórmula (5).

$$
\text { (5) } I A C=\frac{\text { NÚMERO DE CÉLULAS COM AC E AN }}{\text { TOTAL DE CÉLULAS OBSERVADAS X100 }}
$$

A ocorrência de células portadoras de micronúcleos ( $M N)$ e quebras cromossômicas (QC) foram registradas para avaliar instabilidade cromossômica. Estes eventos se não forem reparados pelas células podem gerar futuras mutações e por isso o índice destas anormalidades foi chamado de índice de potencial mutagênico (IPM). O IPM foi calculado segundo a fórmula (6).

(6) $I M T=\frac{\text { NÚMERO TOTAL DE CÉLULAS COM MN E QC }}{\text { TOTAL DE CÉLULAS OBSERVADAS }}$ X100

\subsection{Análises estatísticas}

Todos os resultados foram expressos em Média \pm Desvio Padrão (SD). A normalidade foi realizada pelo teste de Shapiro-Wilks, que mostrou distribuição normal para todos os dados obtidos. Para a análise estatística foi aplicado teste ANOVA, seguido do pós teste de Dunnett, para múltipla comparação entre os grupos. Todos os dados foram analisados pelo programa Graphpad Prism 6.0. 


\section{RESULTADO E DISCUSSÃO}

O presente estudo fez uso de dois diferentes organismos para avaliar os efeitos tóxicos de diferentes concentrações do herbicida Tordon®. Foram expostas sementes de alface (Lactuca sativa) para avaliação da fitotoxicidade por meio dos índices de germinação e crescimento radicular e sementes de Allium cepa para avaliação dos efeitos citogenotóxicos.

De acordo com Araújo et al. (2001), os ensaios realizados com alface são considerados um dos testes toxicológicos mais simples para o biomonitoramento ambiental. Ensaios desse tipo são interessantes pois permitem a avaliação dos efeitos adversos nas fases iniciais do desenvolvimento da semente tornando o processo mais simples e rápido (PALMIERI et al., 2014).

A inibição de germinação de sementes é considerada um biomarcador de efeito letal enquanto que a inibição dos comprimentos de raízes e hipocótilos constituem biomarcadores de efeitos subletais. Os resultados obtidos pela avaliação desses dois biomarcadores são complementares fornecendo parâmetros importantes de toxicidade (SOBRERO; RONCO, 2004).

$\mathrm{Na}$ tabela 2 estão representadas as porcentagens médias das sementes germinadas bem como os resultados da porcentagem relativa de sementes germinadas (SG), a porcentagem de crescimento de raiz (CR) e o índice de germinação (IG).

Tabela 2: Ensaio de germinação e crescimento de raiz para avaliação da fitotoxicidade do herbicida Tordon ${ }^{\circledR}$. Valores demonstrados em Média \pm desvio padrão.

\begin{tabular}{ccccc}
\hline $\begin{array}{c}\text { Concentrações } \\
\text { Tordon }^{\circledR}(\%)\end{array}$ & Sementes germinadas (\%) & SG (\%) & CR (\%) & IG (\%) \\
\hline CN & $82,22 \pm 7,70$ & $100 \pm 0,00$ & $100 \pm 0,0$ & $100 \pm 0,0$ \\
100 & - & - & - & - \\
10 & - & - & - & - \\
1 & - & - & - & - \\
0,1 & $42,22 \pm 3,85^{*}$ & $51,52 \pm 4,66^{*}$ & $12,24 \pm 3,61^{*}$ & $6,24 \pm 1,65^{*}$ \\
0,01 & $51,11 \pm 3,85^{*}$ & $62,70 \pm 9,49^{*}$ & $20,60 \pm 8,56^{*}$ & $12,86 \pm 5,42^{*}$ \\
0,001 & $76,67 \pm 6,67$ & $93,36 \pm 4,25$ & $37,10 \pm 11,05^{\star}$ & $34,53 \pm 10,11^{*}$ \\
0,0001 & $86,67 \pm 6,67$ & $106,53 \pm 18,37$ & $120,03 \pm 11,01$ & $128,13 \pm 26,06$ \\
0,00001 & $82,22 \pm 8,39$ & $100 \pm 3,85$ & $139,35 \pm 16,81^{*}$ & $139,57 \pm 19,69^{*}$ \\
0,000001 & &
\end{tabular}

CN-Controle negativo (água destilada), SG (Porcentagem relativa de sementes germinadas,

CR (Porcentagem de crescimento de raiz, IG (Índice de germinação). *Valores significativos em relação ao controle. $(\mathrm{P}<0,05)$, por meio do ANOVA, pós teste de Dunnet. 
Após 96 horas de exposição foram observadas uma média de 24,3 sementes germinadas no grupo controle enquanto que nas concentrações de $100 \%, 10 \%, 1 \%$ do herbicida a germinação foi inibida. A inibição de germinação pode ser considerada como um efeito letal, significando que as sementes não germinaram, pelo fato de ter ocorrido a morte do embrião (SOBRERO; RONCO, 2004).

Nas concentrações de 0,1\%, 0,01\% e 0,001\% germinaram em média, respectivamente 4,6, 12,6 e 15,3 sementes, apresentando uma redução significativa em relação ao controle. As menores concentrações avaliadas apresentaram a maior quantidade de sementes germinadas sendo 25 para 0,00001\% e 26 para a de 0,000001\%.

A germinação relativa foi significativamente reduzida nas concentrações de $0,1 \%$, 0,01\% e 0,001\% enquanto que para os parâmetros CR e IG a redução foi significativa para 0,01\%, 0,001\% e 0,0001\%. A concentração de 0,000001\% apresentou um aumento significativo nos parâmetros CR e IG em relação ao controle.

A germinação das sementes é uma fase importante no ciclo de desenvolvimento vegetativo, portanto, avaliar a inibição da germinação de sementes expostas à contaminantes neste estágio é a melhor maneira de entender os mecanismos tóxicos dos contaminantes ambientais para as plantas (LIU et al., 2012).

Ainda em relação aos resultados encontrados, de acordo com Junior et al. (2002), quando os índices de germinação são superiores a 20 apontam menor risco de impacto ambiental enquanto que índices menores alertam para um potencial toxico da substância avaliada.

Foram realizadas as medições dos comprimentos de raízes (radícula) e dos comprimentos da parte aérea (hipocótilo) e os valores estão apresentados na tabela 3.

Tabela 3: Medições dos comprimentos das radículas e dos hipocótilos demonstrados em média \pm desvio padrão.

\begin{tabular}{|c|c|c|}
\hline Concentrações Tordon ${ }^{\circledR}(\%)$ & Comprimento da raiz $(\mathrm{mm})$ & Comprimento da parte aérea $(\mathrm{mm})$ \\
\hline $\mathrm{CN}$ & $9,74 \pm 2,22$ & $10,02 \pm 1,85$ \\
\hline 100 & - & - \\
\hline 10 & - & - \\
\hline 1 & - & - \\
\hline 0,1 & - & - \\
\hline 0,01 & $1,14 \pm 0,13^{*}$ & $1,11 \pm 0,23^{*}$ \\
\hline 0,001 & $1,88 \pm 0,49^{*}$ & $0,76 \pm 0,15^{*}$ \\
\hline 0,0001 & $3,46 \pm 0,43^{*}$ & $5,61 \pm 0,31^{*}$ \\
\hline 0,00001 & $11,55 \pm 1,68$ & $11,55 \pm 1,52$ \\
\hline 0,000001 & $13,36 \pm 1,67^{*}$ & $11,43 \pm 0,77$ \\
\hline
\end{tabular}

CN-Controle negativo. *Valores significativos em relação ao controle. $(\mathrm{P}<0,05)$, por meio do ANOVA, pós teste de Dunnet. 
Os comprimentos de raiz apresentaram uma diminuição significativa para as concentrações de 0,01\%, 0,001\% e 0,0001\% assim como nos comprimentos dos hipocótilos. E na concentração de $0,000001 \%$ foi observado um aumento significativo no comprimento da raiz.

O 2,4-D é um herbicida auxínico, portanto reproduz a ação do ácido indolacético, que é uma auxina natural (GROSSMAN, 2003). De acordo com Taiz e Zeiger (2004), baixos níveis dessa auxina são necessários para o alongamento da raiz, mas em altas concentrações atuam inibindo o crescimento da raiz como observado nesse trabalho.

Segundo Sobrero e Ronco (2004) a inibição de crescimento de raiz é um indicador de efeito subletal, pois algumas doses não são tão altas para inibir a germinação, mas podem retardar o crescimento de raiz.

Nascimento e Yamashita (2009), estudaram parâmetros de emergência de plântulas, altura e fitointoxicação de olerícolas (pepino, alface e tomate) cultivados em solo previamente contaminado com o herbicida Tordon ${ }^{\circledR}$. De acordo com os autores a emergência e a altura das plantas foram reduzidas em doses acima de 0,04 L há ${ }^{-1}$. Esses resultados demonstraram a alta sensibilidade dessas espécies aos herbicidas auxínico, levando a mudanças no metabolismo vegetal.

Por meio das análises citogenéticas foi possível avaliar os efeitos do herbicida Tordon ${ }^{\circledR}$ sobre o material genético de $A$. cepa.

O índice mitótico que é caracterizado pelo total de células em divisão, apresentou uma redução significativa comparado ao controle apenas na concentração de $0,01 \%$. As concentrações de $0,1 \%$ e $0,001 \%$ apresentaram índices menores, porém não foram significativas. Na concentração $100 \%$ não foi possível a avaliação uma vez que a germinação das sementes foi inibida completamente.

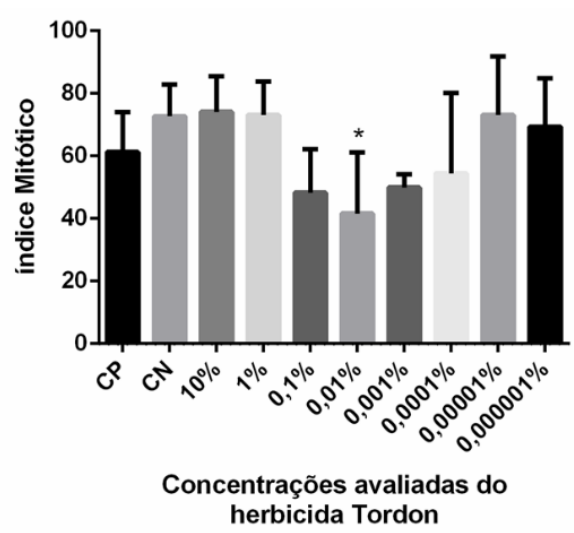

Figura 1: Resultados obtidos para o índice mitótico em raízes de $A$. cepa expostos a diferentes concentrações de Tordon. 
O índice de genotoxicidade obtido por meio da observação das aberrações cromossômicas e das alterações nucleares está representado na figura 2. De acordo com os resultados apenas a exposição à concentração de $10 \%$ foi significativamente genotóxica. Pelos resultados observados é possível inferir que todos os tratamentos, com exceção, da menor concentração avaliada apresentaram um aumento no número de alterações cromossômicas e nucleares, porém não foram significativas provavelmente devido ao desvio padrão. Sobre os resultados observados ainda é possível inferir que a substância avaliada apresenta uma curva dose resposta. Aparentemente, quanto maior a diluição menos alterações cromossômicas e nucleares são observadas.

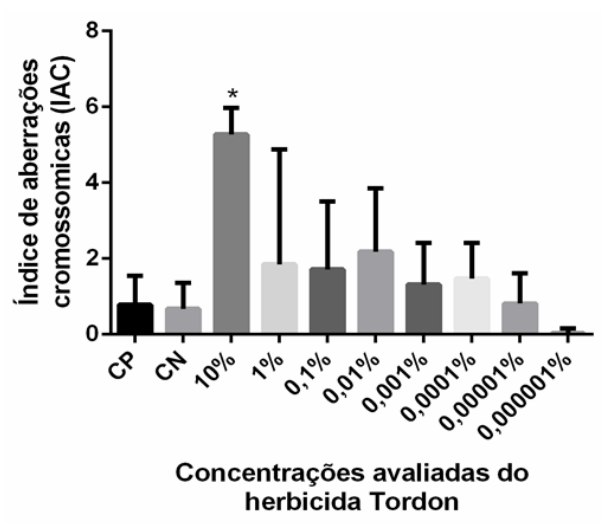

Figura 2: Resultados obtidos pelos índices de aberrações cromossômicas e nucleares (genotoxicidade) em raízes de $A$. cepa expostos a diferentes concentrações de Tordon.

O índice de potencial mutagênico (IPM) foi calculado pela observação das células portadoras de micronúcleos (MN) e quebras cromossômicas (QC). Os resultados encontrados estão representados na figura 3.

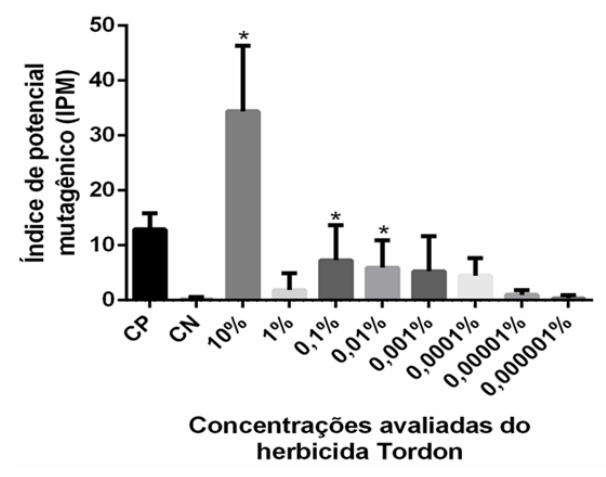

Figura 3: Resultados obtidos pelos índices de potencial mutagênico em raízes de $A$. cepa expostos a diferentes concentrações de Tordon. 
As concentrações de 10\%, 0,1\% e 0,01\% apresentaram valores significativos nos índices de potencial mutagênico. Pelos resultados observados é possível inferir que o potencial mutagênico diminui à medida que aumenta a diluição da substância.

Os micronúcleos encontrados nas concentrações citadas acima indicam ação mutagênica do composto. A formação destas estruturas ocorre através de danos, reparados erroneamente ou não reparados, nas células parentais, sendo facilmente observáveis nas células filhas como uma estrutura similar ao núcleo principal, mas com tamanho reduzido. Portanto, o micronúcleo se desenvolve a partir de algumas aberrações cromossômicas, como perda e quebra cromossômica, ou pode surgir por outros processos como poliploidização, onde são originados pela eliminação de DNA excedente do núcleo principal a fim de restaurar a condição normal de ploidia (FERNANDES et al., 2007). Alguns danos genotóxicos encontradas nas células expostas ao Tordon estão apresentadas na figura 4.

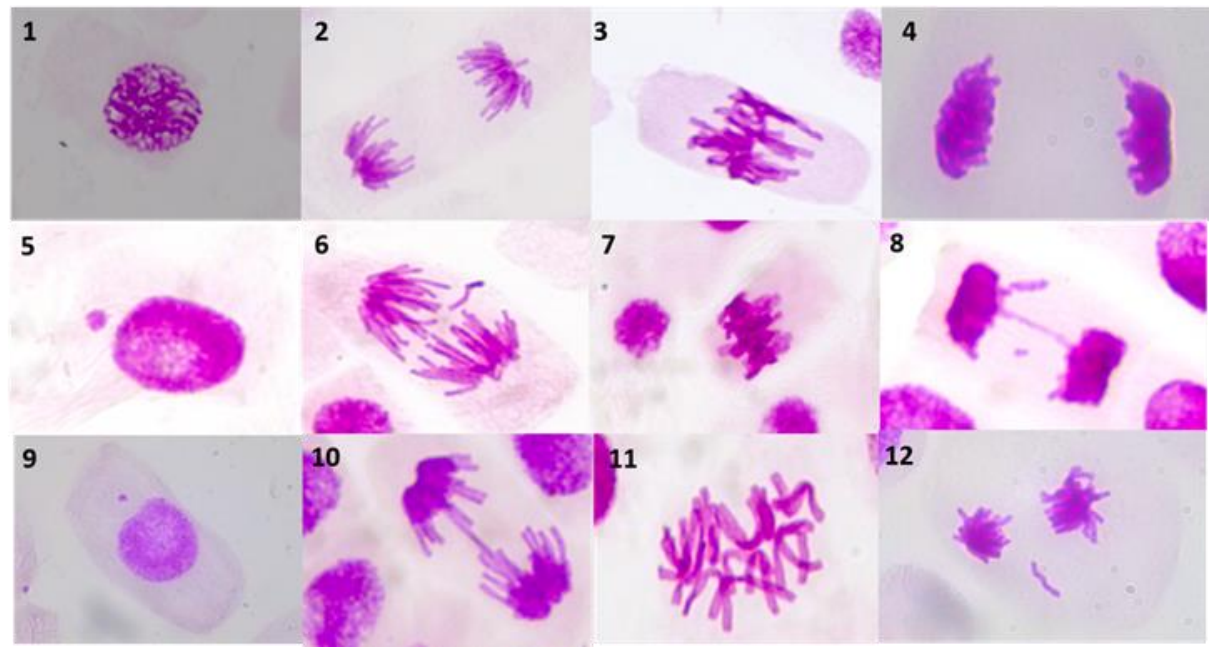

Figura 4: Danos genotóxicos e de indicativo de mutagenicidade observados nas células meristemáticas de A. cepa expostas a diferentes concentrações do herbicida Tordon. 1- Prófase; 2- Anáfase; 3- Metáfase; 4Telófase; 5- Interfase com Micronúcleo; 6- Anáfase com perda cromossômica; 7- Metáfase com aderência; 8Telófase com ponte e quebra; 9- Prófase com micronúcleo; 10- Anáfase com ponte; 11- C-metáfase; 12Telófase com perda cromossômica.

\section{CONCLUSÃo}

De acordo com os resultados observados é possível inferir que o herbicida Tordon induziu o desenvolvimento de efeitos citogenotóxicos nos dois organismos teste utilizados (Lactuca sativa e A. cepa). Resultados significativos foram observados para as maiores 
concentrações avaliadas $(10 \%, 1 \%, 0,1 \%)$ revelando um efeito dose resposta (quanto menor a concentração menor o efeito citogenotóxico). Estes resultados são importantes pois revelam que mais pesquisas devam ser realizadas com esse herbicida, uma vez que a exposição a essa substância pode colocar em risco a saúde humana.

\section{REFERÊNCIAS}

ADAPAR. Disponível em: <http://www.adapar.pr.gov.br/arquivos/File/defis/DFl/Bulas/ Herbicidas/TORDON.pdf> acesso em: 25/02/2018

CARVALHO, T.C; SILVA, S.S.; SILVA, R.C.; PANOBIANCO, M.; MÓGOR A.F. Influência de bioestimulantes na germinação e desenvolvimento de plântulas de Phaseolus vulgaris sob restrição hídrica. Revista de Ciências Agrárias, v. 36, n.2, p. 199-205. 2013

COPATTI, C.E.; GARCIA, L.O.; BALDISSEROTTO, B. Uma importante revisão sobre o impacto de agroquímicos da cultura de arroz em peixes. Biota Neotropica. v.9, n.4, p. 23542. 2009

CUNHA, C.S.M.; TILLMANN, M.A.A.; VILLELA, F.A.; DODE, L.B.; BALERINI, F. Comparação de métodos na detecção de sementes de soja geneticamente modificada resistente ao glifosato. Métodos para detecção de semente de soja GM Revista Brasileira de Sementes, v. 27, n. 1, p.167-75, 2005

DIAZ, M.C.C. SANTIAGO, J.L.R.; LUNA, J.L. Métodos ecotoxicológicos para la evaluación de suelos contaminados con hidrocarburos, 1. ed., 2012 (livro)

DOWLER, C.C.; FORESTIER, W.; TSCHIRLEY, F.H. Effect and Persistence of Herbicides Applied to Soil in Puerto Rican Forests. Weed Science, Porto Rico, v.16, n.1, p.45-50. 1968 EPPS, G.A.V. Control of Gambel Oak with Three Herbicides. Journal of Range Management, v.27, n.4, p.297-301. 1974

FISKESJO G. The Allium Test II: Assesmente of chemical's genotoxic potential by recording aberrations in chromosomes and cell divisions in root tips of Allium Cepa $L$. Environ Toxicology, v.9, p.234-41. 1994 
GRANT, W.F. Chromossome aberration assays in Allium. A report of the U.S. environmental protection agency. Gene-Tox program. Mutation Research, v. 99, n.3, p. 273-91. 1982

GRISOLIA, C.K. Agrotóxicos: mutação, câncer e reprodução. Brasília: Editora Universidade de Brasília, 2005. 392 p.

HILL, R.H. JR. TO, T. HOLLER, J.S.; FAST, D.M.; SMITH, S.J.; NEEDHAM, L.L.; BINDER, S. Residues of Chlorinated Phenols and Phenoxy Acid Herbicides in the Urine of Arkansas Children. Archives of Environmental Contamination Toxicology. v.18, n.4, p.469-74. 1989

ISENSEE, R.; JONES, G.E.; TURNER, B.C. Root Absorption and Translocation of Picloram by Oats and Soybeans. Weed Science, v.19, n.6, p. 727-31. 1971

J ONG - W O OPARK, JERZYDEC, JANG - E OKKIM, A N D J E A N - M A R C B O L L A G. Effect of Humic Constituents on the Transformation of Chlorinated Phenols and Anilines in the Presence of Oxidoreductive Enzymes or Birnessite. Environmental Science and Technology. v.33, p.2028-34, 1999

KLINGMAN D.L.; GORDON, C.H.; YIP, G.; BURCHFIELD, H.P. Residues in the forage and in Milk from Cows Grazing Forage Treated with Esters of 2,4-D. Weeds, n.2, v.14, p.164-67. 1966

LEME, D.M.; MARIN-MORALES, M.A. Allium cepa Test in environmental monitoring: a review on its application. Mutation Research - Mutation Research, v. 682, p. 71-81, 2009.

LUTTERBECK, C.A.; KERN, D.I.; MACHADO, E.L.; KUMMERER, K. Evaluation of the toxic effects of four anti-cancer drugs in plant bioassays and its potency for screening in the context of waste water reuse for irrigation. Chemosphere v.135, p.403-10. 2015

MANSANO, A. S.; MOREIRA, R. A.; ROCHA, O. Toxicidade aguda do agrotóxico Carbofurano ao cladocero Ceriodaphnia silvestrii Daday, 1902. Periódico Eletrônico Fórum Ambiental da Alta Paulista, IX Fórum Ambiental d a Alta Paulista, v. 9, n. 11, p. 91-103. 2013 
MAZZEO, D.E.C.; FERNANDES, T.C.C.; MARIN-MORALES, M.A. Cellular damages in the Allium cepa test system, caused by BTEX mixture prior and after biodegradation process. Chemosphere, v. 85, p. 13-18. 2011.

NASCIMENTO, E.R.; YAMASHITA, O.M. Desenvolvimento inicial de olerícolas cultivadas em solos contaminados com resíduos de 2,4-d + picloram. Semina: Ciências Agrárias, v.30, n.1, p.47-54. 2009

NEARY, D.G.; DOUGLASS, J.E.; FOX, W. Low picloram concentrations in streamflow resulting from forest application of tordon-10k3. Weed, v.32, p.182-97. 1979

OAKES, D.J.; POLLAK, J.K. Effects of a herbicide formulation, Tordon 75D®, and its individual components on the oxidative functions ofmitochondria. Toxicology. v.136, n.1, p.41-52. 1999

PALMIERI, M.J.; LUBER, J.; ANDRADE-VIEIRA, L.F.; DAVIDE, L.C. Cytotoxic and phytotoxic effects of the main chemical components of spent pot-liner: A comparative approach. Mutation Research/Genetic Toxicology and Environmental Mutagenesis, v. 763, p.30-35, 2014.

RAMALHO, J.F.G.P.; SOBRINHO, N.M.B.A.; VELLOSO, A.C.X. Contaminação da microbacia de Caetés com metais pesados pelo uso de agroquímicos. Pesquisa Agropecuaria, v.35, n.7, p.1289-303, 2000

SANTOS, M.V. FREITAS, F.C.L., FERREIRA, F.A., VIANA, R.G., TUFFI SANTOS, L.D; FONSECA, D.M. Eficácia e persistência no solo de herbicidas utilizados em pastagem. Planta Daninha, v. 24, n. 2, p. 391-98, 2006

STEIERT J.G.; PIGNATELLO J.J.; CRAWFORD R.L. Degradation of Chlorinated Phenols by a Pentachlorophenol-Degrading Bacterium. Applied and environmental microbiology, v.53, n.5, p. 907-10. 1987

UFMG - Instituto de Ciências Biológicas, Depto. Biologia Geral. Laboratório de Ecologia de Bentos. Disponível em: <http://www.icb.ufmg.br/labs/benthos/index_arquivos/Page1631.htm> acesso em: maio de 2015 
VINHA, M. B.; PINTO, C.L.O.; PINTO, C.M.F.; SOUZA, C.F. SOUZA, M.R.M. OLIVEIRA, L.L. Impactos do uso indiscriminado de agrotóxicos em frutas e hortaliças. Revista Brasileira de Agropecuária Sustentável (RBAS), v.1, n.1, p. 98-103. 2011

WYRILL, J.B.; BURNSIDE, O.C. Absorption, Translocation, and Metabolism of 2,4-D and Glyphosate in Common Milkweed and Hemp Dogbane. Weed Science, v.24, n.6, p.557-66. 1976

ZAHM, S.H.; WEISENBURGER, D.D.; BABBIT, P.A.; SAAL, R.C. VAUGHT, J.B.; CANTOR, K.P.; BLAIR, A.A Case-Control Study of Non-Hodgkin's Lymphoma and the Herbicide 2,4Dichlorophenoxyacetic Acid (2,4-D) in Eastern Nebraska. Epidemiology. v.1, n.5, p.349-56. 1990 